\title{
Bóvedas tabicadas en la ingeniería militar española (s. XVIII)
}

\section{Tile vaults in Spanish military Engineering (XVIII century)}

\author{
Josep Lluis i Ginovart $^{(*)}$, Cinta Lluis-Teruel ${ }^{(*)}$, Iñigo Ugalde-Blázquez ${ }^{(*)}$
}

\section{RESUMEN}

El Duque de Belle-Isle y el Conde de Espié habían conocido en sus campañas de la Guerra de Sucesión (1701-1715) la voûte à la Roussillon. Estas bóvedas tabicadas obtuvieron una buena crítica en toda Europa y también en España (donde eran conocidas desde el siglo XIV) gracias a la difusión de los textos del Conde de Espié (1754) y de Pierre Patte (1777). Se determina qué uso tuvieron las bóvedas tabicadas desde el punto de vista de la construcción militar, favorecidas por sus supuestas cualidades mecánicas, y cuál fue la repercusión entre los ingenieros militares españoles del siglo XVIII. El estudio concluye que la localización de los proyectos realizados con esta técnica por ingenieros militares en el Levante español, coincide con los lugares donde ya existía una mano de obra especializada y que conocía esta técnica constructiva.

Palabras clave: Ingenieros militares; Academia de Matemáticas, bóvedas tabicadas; Conde de Espié.

\section{ABSTRACT}

The Duke of Belle-Isle and the Count of Espié had known in their crusades of the War of Succession (1701-1715) la voûte à la Roussillon. These tile vaults received good feedback throughout Europe as well as in Spain (where they were well-known since the 14th Century) thanks to the dissemination of the texts of the Count of Espie (1754) and Pierre Patte (1777). We determine which use the tile vaults had from the point of view of military construction, favoured by their supposed mechanical qualities, and what the repercussion was among Spanish military engineers in the 18th Century. The survey concludes that the location of the projects carried out through this technique by military engineers in Eastern Spain coincides with the places where a specialized workforce already existed, and that people in these places already knew such construction technique.

Keywords: Military engineers; Mathematics Academy; tile vault; Count of Espié.

(*) Universitat Internacional de Catalunya

Persona de contacto/Corresponding author: jlluis@uic.es (Josep Lluis i Ginovart)

ORCID: http://orcid.org/oooo-0oo1-5957-762X (J. Lluis), http://orcid.org/oooo-0oo2-5280-1147 (C. Lluis); http://orcid. org/oooo-0002-4133-9508 (I. Ugalde)

Cómo citar este artículo/Citation: Josep Lluis i Ginovart, Cinta Lluis-Teruel, Iñigo Ugalde-Blázquez (2021). Bóvedas tabicadas en la ingeniería militar española (s. XVIII). Informes de la Construcción, 73(562): e393. https://doi.org/10.3989/ic.800oo

Copyright: (C) 2021 CSIC. Este es un artículo de acceso abierto distribuido bajo los términos de la licencia de uso y distribución Creative Commons Reconocimiento 4.0 Internacional (CC BY 4.0). 


\section{INTRODUCCIÓN}

Dos militares franceses, el mariscal de Francia Charles Fouquet, Duque de Belle-Isle (1684-1762) y el comandante Félix François, Conde de Espié (1708-1792), utilizaron la bóveda tabicada para la construcción de sus viviendas, contratando sendos arquitectos de prestigio. El primero encargó al arquitecto Pierre Contant D'Ivry (1698-1777) la construcción del Castillo de Bizy (1740) en Vernon, en el Valle del Loira (Figura 1) ('), y el segundo, el Hôtel d'Espie (1750), proyectado por Jean-Baptiste François Hyacinthe de Labat de Savignac (1709-1784) en Toulouse. Ambos militares habían conocido el sistema constructivo de la Voûte à la Roussillon $\left({ }^{2}\right)$ en sus campañas por Occitania. El Duque de Belle-Isle participó en la Guerra de Sucesión (1701-1715) y la de la Cuádruple Alianza (1718-1720), mientras que el Conde de Espié fue Gobernador de Muret (1748) en el Alto Garona.

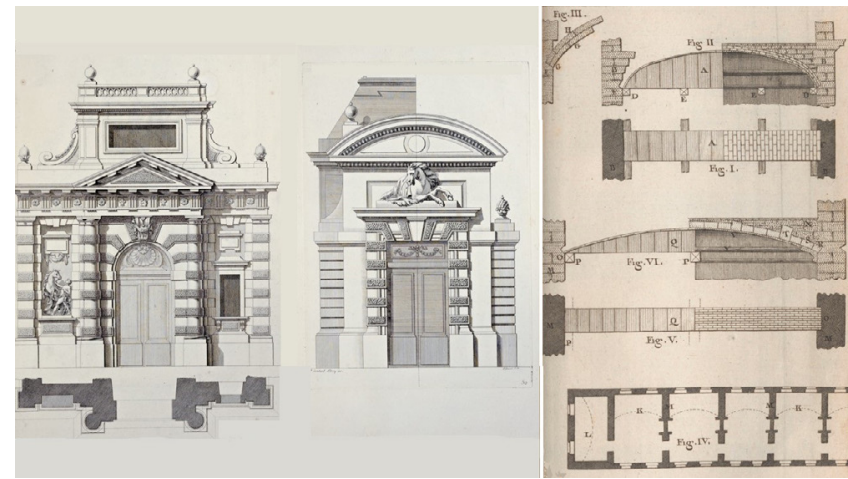

Figura 1. Bóvedas tabicadas Caballerizas en Castillo de Bizy a), b) P.Contant d'Ivry. Les Oeuvres d'architecture de Pierre Contant d'Ivry (1769); c) P. Patte, Planches por le sixiéme volumen du cours d'Architecture (1777)

En este contexto, el objetivo es determinar qué uso tuvieron este tipo de bóvedas desde el punto de vista de la construcción militar y averiguar cuál fue la repercusión entre los ingenieros militares españoles del siglo XVIII. Hay que tener en cuenta la influencia de la estrategia militar francesa después de la Guerra de Sucesión (1701-1715) en el reinado de Felipe V (1683-1746), que fue quien creó el cuerpo de Ingenieros militares (1711) y la Academia de Matemáticas de Barcelona (1720) para su formación.

El estudio se limita a la interpretación de las representaciones gráficas de los proyectos de los ingenieros pertenecientes al Catálogo Colectivo de las Colecciones de Mapas, Planos y Dibujos de los Archivos Estatales del Ministerio de Cultura (http://www.mcu.es/ccbae/es/mapas/principal.cmd) y a la Colección de Mapas, Planos y Dibujos del Archivo General de Simancas, así como a la cartoteca del Ministerio de Defensa junto a la consulta del Archivo General de Segovia, del Archivo General Militar de Madrid y de Museo Naval de Madrid (https://patrimoniocultural.defensa.gob.es/es/busqueda). Existen por tanto las limitaciones de la escala de dichos proyectos y por tanto de los grosores de los elementos constructivos, que han sido analizados por comparación. El estudio va a permitir localizar geográficamente aquellos lugares donde este sistema constructivo, apoyado en la técnica local y en sus supuestas cualidades mecánicas, fue utilizado por los Ingenieros desde el inicio del Cuerpo (1711), aunque era conocido en la Corona de Aragón desde el siglo XIV (3)

\subsection{El redescubrimiento de la voûte à la Roussillon o volta de maó}

Félix François, Conde de Espié, había presentado un Proyecto de Escuela Militar (1751) a Luis XV de Francia (17101774), publicado después como Réflexions du Comte. Sur l'établissement de l'École militaire (1756) (4). En este paréntesis, publicó la Maniere de rendre toutes sortes d'édifices incombustibles (1754), del que dice que instruye para la utilización de bóvedas tabicadas para salvaguardar las plazas fuertes del fuego enemigo (5) (Figura 2.a).

La traducción española, Modo de hacer incombustibles los edificios (1776), fue realizada por Joaquín de Sotomayor Cisneros y Sarmiento (f. 1776) ${ }^{6}{ }^{6}$. Pese a ello, este sistema tabicado es cuestionado por la l'Académie royale d'Architecture (1747) ante la demanda de los Padres Capuchinos para la construcción del convento de Montauban, a pesar de reconocer que la técnica ya había sido introducida por esta Orden en el convento de Castelnaudary, en el Languedoc ( ${ }^{7}$ ). La discusión del monolitismo y el empuje de las bóvedas tabicadas entre el Conde de Espié y la contestación de Ventura Rodríguez (1717-1785) en la Censura de la obra de Sotomayor (1776) ha sido ampliamente difundida $\left({ }^{8}\right)\left({ }^{9}\right)$.

El comportamiento ante el fuego de estas bóvedas será uno de los argumentos a favor de la llamada construcción cohesiva por Rafael Guastavino Moreno (1842-1908) en el Essay on the Theory and History of Cohesive Construction applied especially to the timbrel vault (1892) ${ }^{\left({ }^{10}\right)}$. Éste la define como la que se realiza por la asimilación de los diferentes materiales, frente a la que denomina construcción mecánica que trabaja por gravedad, habitualmente utilizada por los ingenieros militares ${ }^{11}$ ) (Figura 2.c).
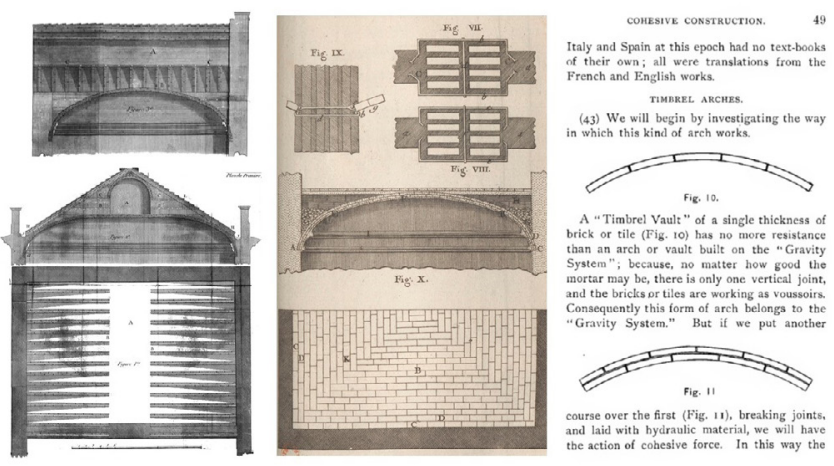

Figura 2. a) Conde de Espié (1765); b) Pierre Patte (1777), c) Rafael Guastavino (1892)

\subsection{Félix François, Conde de Espié, y la Academia de Bellas Ares de San Fernando}

Diego de Villanueva (1713-1774) fue director de Arquitectura de la Academia de Bellas Artes de San Fernando (1756) y difundió su doctrina en la Colección de diferentes papeles críticos sobre todas las partes de la Arquitectura (1766) $\left({ }^{12}\right)$. En la Carta 1 cita como autores de referencia al Abbè Marc-Antoine Laugier, (1713-1769) y sus Essai sur l'architecture P. Lauguier (1745) $\left({ }^{13}\right)$, obra estructurada también a manera de cartas en las que se abordan temas similares. Cita también las Mémoires critiques de l'architecture (1702) de Michel de Frémin (f. 1686) ( ${ }^{14}$ ), el Mecu- 
re de France (1747) ${ }^{(5)}$ y la carta VII a Amadée Francois Frezier ${ }^{(16)}$.

En el texto de la Carta ${ }^{\circ}$ VI Sobre el arte de fabricar; y fraudes a los Obreros, similar al del Abbè Laugier (1745), cita al Conde de Espié. En su obra especifica que los Comble Briqueté son edificios que se techan sin la utilización de madera o hierro, tan solo con ladrillos planos, colocados con yeso y mortero de cal y arena y construidos sobre Voutes Plates. Como militar se refería este tipo de construcciones para salvaguardar, en las plazas fuertes, los almacenes y arsenales del fuego propio. Concluye también que este tipo de construcciones no producen empujes dado que los tabiques de las lengüetas hacen la función de atirantamiento provocando un funcionamiento estructural monolítico. En la traducción de la obra del Conde de Espié realizada por Joaquín de Sotomayor (1776), se introducen adiciones y se incorpora el saber de las Observations sur l'Architecture (1765) de Marc-Antoine Laugier (1713-1769) ${ }^{(17)}$. En la censura de la obra, Ventura Rodríguez (1717-1785) aborda el empuje de las bóvedas, contradiciendo a Espié cuya teoría y efecto de los empujes ya había sido descrita por Fray Lorenzo de San Nicolas (1593-1679).

En la Carta IX Sobre la arquitectura en España, y a los autores que han escrito de ella, cita dieciocho textos esenciales entre los que existen los referidos a la construcción de bóvedas como el Arte y Uso de la Arquitectura de Fray Lorenzo de San Nicolas (1593-1679). De esta obra se podía disponer en la edición prínceps, de la Primera parte (1639) $\left({ }^{18}\right)$ y de la Segunda parte (1665) ${ }^{19}$ ); en la segunda edición, de la Primera parte (1667) de Bernardo de Hervada; y en la edición conjunta, de la Primera y Segunda parte (1736) de Manuel Román. Se refiere también al Breve Tratado de todo Genero de bobedas (1661) de Juan de Torrija (1604-1666) (20) y la Escuela de Arquitectura Civil (1738) de. Athanasio Genaro Brizguz y Bru (1713-?) ( $\left.{ }^{21}\right)$.

Cronológicamente fueron apareciendo otras obras de arquitectura civil como la de Johann Jacob Schübler (1689-1741) Das ist: Kurtze und leichte Verfaßung der Practicabelsten Regul, zur Perspectivischen Zeichnungs-Kunst (1749) (22). También la de otros arquitectos repudiados por los académicos, al igual que el Conde de Espié. Tal es el caso de El Arquitecto Práctico, Civil, Militar, y Agrimensor (1767) de Antonio Plo y Camín (f. 1761-1770) $\left({ }^{23}\right)$ y el Cours d'architecture (1771-1777), empezado por Jacques-François Blondel (17051774) y terminado por Pierre Patte, (1723-1814) (Figura 2.b), donde en el Tomo VI, Capítulo II [fol. 84-125(1777)] (24) y en

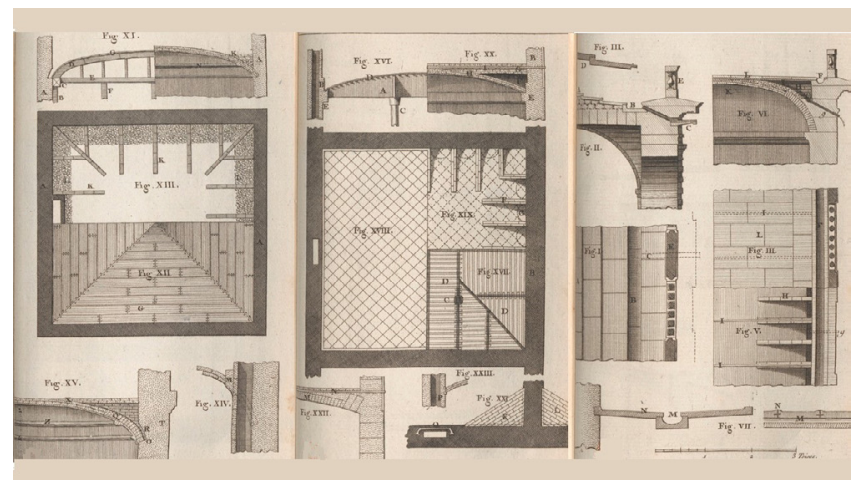

Figura 3. Bóvedas tabicadas P. Patte, Planches por le sixiéme volumen du cours d'Architecture (1771) el de la explicación con sus planchas [Pla. 54-59 (1777)] (25), hace una amplia valoración de la construcción con bóvedas tabicadas (Figura 3).

\section{EL SABER ILUSTRADO DE LOS INGENIEROS MILITARES DEL SIGLO XVIII}

El Rey Felipe V (1683-1746) nombrará a Jorge Prosper Verboom (1665-1744) Ingeniero General y a Mateo Calabro (1680-1748) director de la Academia de Matemáticas de Barcelona (1720-1738), cargo que desempeñará posteriormente Pedro de Lucuze y Ponce (1692- 1779) entre el periodo (17381779). En los planes de estudio de la Academia bajo Calabro (1724), Verboom (1739) y Pedro de Lucuze (1738) $\left({ }^{26}\right)$, los textos fueron Los seis libros primeros de la geometría de Euclides (1576) de Rodrigo Zamorano (1542-1620), los Nouveaux Éléments de géométrie (1667) de Antoine Arnauld (16121694), La geometrie des lignes et des surfaces rectilignes et circulaires (1712) de Jean-Pierre de Crousaz (1663-1750), el Compendio Mathemático (1707-1715) de Tomás Vicente Tosca (1651-1723), le Nouveau cours de Mathématiques (1725) de Bernard Forest de Belidor (1698-1761) y el Traité d'Architecture (1714) de Sébastien Le Clerc (1637-1714).

La Real Academia Militar de Matemáticas de Barcelona imprimió bajo su iniciativa algunos textos. Así, se traduce la obra de John Müller (1699-1784), A treatise containing the elementary part of fortification, regular and irregular (1755), por Miguel Sánchez Taramas (1733-1799) (27) (Figura 4.a) y se publican Los Principios de Fortificación (1772) de Pedro de Lucuze $\left({ }^{28}\right)$ y las Nociones Militares o Suplemento a los Principios de Fortificación (1781) de José Ignacio de March (f. 1781) (29). Otro recurso formativo son los apuntes obligatorios recogidos por los alumnos de la Academia sobre el Tratado VIII de la Arquitectura Civil dictados por Pedro de Lucuze en el periodo (1739-1779) $\left.{ }^{(30}\right)$.

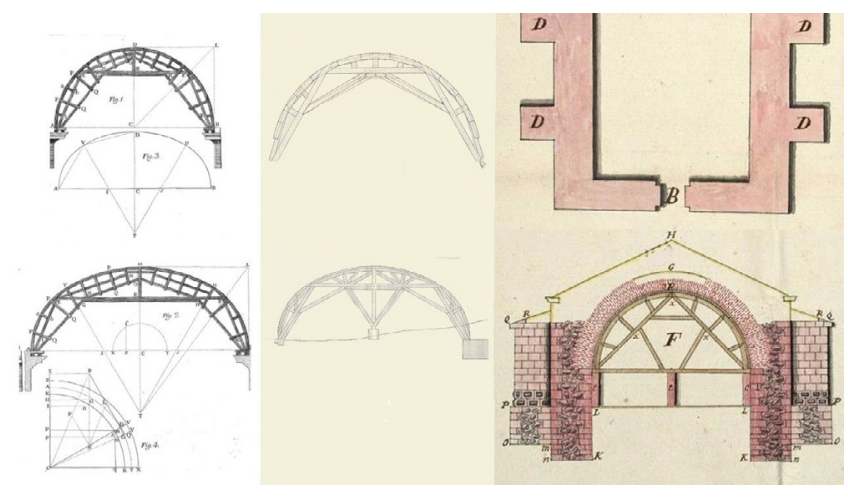

Figura·4. La influencia de los Tratados: a) Cimbras Miguel Sánchez Taramas, Tratado de fortificación (1769); b), c) proyectos Ingenieros militares

Por su parte, otra de las fuentes directas a que tenían acceso eran las bibliotecas. Tal era el caso de la de la Academia de Matemáticas ( ${ }^{31}$ o la de los propios militares. La biblioteca de Jorge Prosper Verboom (1665-1744) disponía de 157 libros $\left({ }^{2}\right)$, la de Francisco Sabatini (1721-1797) de 628 (33), la Pedro Martín Cermeño (1722-1790) de $637{ }^{34}$ ), la de José Agustín Hermosilla y Sandoval (1703-1776) de 189, la de Clemente Aedo Espina $(+1787)$ de 72 , la de Ricardo Ailmer Burgo $(+1788)$ de 40 y la Miguel de Roncali $(+1794))$ de un total de $101(35)$. 


\subsection{El saber Ilustrado en la Academia de Matemáti- cas de Barcelona en el siglo XVIII}

Las obras capitales en la formación y referencia de los ingenieros fueron el Compendio Matemático (1707-1715) de Tomás Vicente Tosca ${ }^{\left({ }^{6}\right)}$, el Nouveau cours de Mathématique (1725) y La science des ingénieurs (1729) de Bernard Forest de Belidor ( ${ }^{37}$ ). Las obras de Tosca aparecieron en la biblioteca de la Academia, Verboom, Cermeño y Hermosilla y las de Forest de Belidor en las de la Academia, Verboom, Aedo Espina, Ailmer, Cermeño Roncali y Sabatini.

Tomás Vicente Tosca dedica el Tratado XVI del Tomo V del Compendio Mathemático, dividido en seis libros, a la arquitectura militar $\left(^{38}\right)$. El tratado va precedido por uno de Arquitectura Civil y otro, el Tratado XV, dedicado especialmente a De la Montea y Cortes de Cantería [fol. 81-252 (1712)]. En este hace referencia al arco tabicado, que sólo sirve para el falseado. En dicho arco se irán juntando y uniendo los ladrillos por la rosca, siguiendo la cimbra o cerchón [fol. 96 (1712)]. Trata también el tema del dimensionamiento de arcos y bóvedas, así como de su mecanismo de colapso, y determina que la forma perfecta del arco es uno mixto, formado por el intradós del arco de medio punto y el trasdós del arco apuntado [fol. 118 (1712)].

En cuanto a las obras de Bernard Forest de Bélidor, en le Nouveau cours de Mathématique (1725), el autor cita una aplicación práctica de la mecánica de fábrica para la construcción de almacenes de pólvora [fol. 490-498(1725)], determina el estribado para una bóveda de cañón y para un arco apuntado con una curvatura de tercio punto, y sintetiza en una tabla la dimensión de los pieds droits en función de su curvatura y su localización matizando, a la vez, si están situados en un sótano o en la cubierta. En La science des ingénieurs dans la conduite des travaux de fortification et architecture civile (1729), plantea la curvatura que conviene dar a una bóveda, para que todas sus partes pesen lo mismo y estén en equilibrio [L.II fol. 43-45 (1729)] y cuyo resultado será una curva con forma de catenaria. Por ello, determina en las construcciones militares hasta cinco topologías de bóvedas diferentes: las de medio punto, las apuntadas a tercio punto, las elípticas dibujadas como arco rebajado, las planas y las derivadas de la cadena ( ${ }^{39}$ ).

Algunos ingenieros disponían de textos útiles para la construcción de bóvedas anteriores a la mecánica ilustrada. Es el caso de alguna de las ediciones del Arte y uso de la Arquitectura de Fray Lorenzo de San Nicolás en la biblioteca de Cermeño,

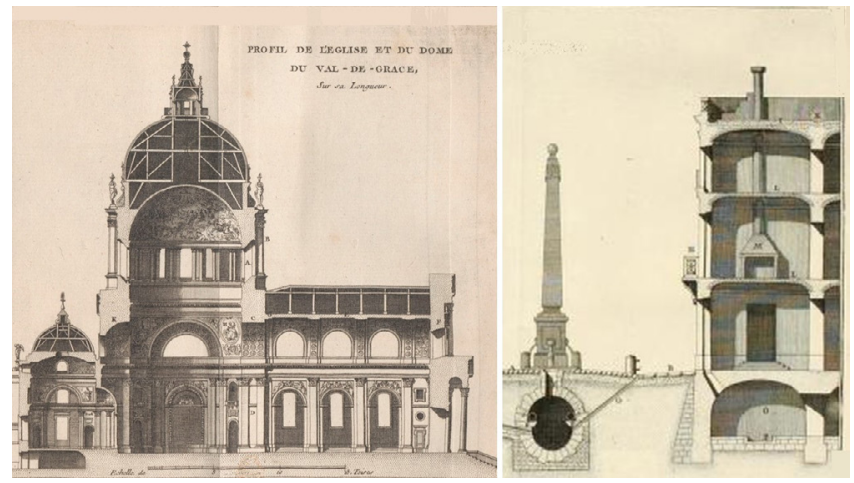

Figura·5. Pierre Patte a) Cours d'architecture (1777); b) Mémoires sur les objets les plus importans de l'architecture (1769) donde el autor explica en el primer tomo la ejecución y estribo de las bóvedas tabicadas [fol. 90-103 (1639)]. Otras de estas referencias son L'architecture des voûtes (1643) de François Derand (1588 -1644) en la Verboom y el tratado de estereotomía de La pratique du trait à preuve de M. des Argues Lyonnois pour la coupe des pierres en Architecture (1643) de Abraham Bosse (1604-1676) en la de la Academia de Barcelona.

Entre los libros de arquitectura, aparecen las ediciones de Vitrubio: Sabatini disponía de la edición de Cesare Cesariano (1521) y de la de Claude Perrault llamada Les dix livres d" architecture de Vitruve, (1673) y junto con Verboom y Hermosilla disponía además de la traducción de José de Castañeda (1766), publicada como Compendio de los diez libros de Arquitectura de Vitruvio (1761). Sabemos que Cermeño poseía una edición de Serlio y Verboom del Extraordinario Libro di Architettura (1551) y Sabatini poseía una edición del Quinto libro d'architettura (1547) y de Tutte l'opere d'architettura (1584), completando su biblioteca I quattro libri de l"Architettura (1570) de Palladio, Le due regole della prospettiva pratica (1583) de Vignola y de Dell'Idea dell'Architettura Universale (1615) de Scamozzi.

En cuanto a la tratadística francesa, Verboom disponía del Cours d'architecture qui comprend les ordres de Vignole (1691) de Agustín-Charles d'Avilier y en la biblioteca de Sabatini estaban les Ordonnance des cinq especes de colonnes selon la methode des Ancienos (1683) de Perrault, La theorie et la pratique de la coupe des pierres (1737-1739) de Frezier, Mémoires sur les objets les plus importans de l'architecture (1769) de Patte y el Cours d'architecture (1771-1777) de Blondel con Patte y (Figura·5).

\section{PROYECTOS DE BÓVEDAS TABICADAS EN LOS INGENIEROS MILITARES DEL SIGLO XVIII}

Dos hechos cronológicamente próximos pero anteriores a la creación de la Academia de Matemáticas de Barcelona (1720) tuvieron especial trascendencia desde el punto de vista constructivo y de la representación gráfica de la arquitectura militar respecto al proyecto y ejecución de bóvedas tabicadas. El primero, la Real Orden de 9 de marzo de 1715 del Rey Felipe V (1683-1746), mandando realizar un proyecto para construir una Ciudadela en Barcelona. Jorge Prosper Verboom (16651744), su Ingeniero General, será quien realice el proyecto. La construcción de Ciudadela fue un banco de pruebas tanto desde la perspectiva de la fortificación como del proyecto de construcción del arsenal ( $\left.{ }^{40}\right)$. El segundo, la Real Ordenanza e Instrucción de 4 de julio de 1718 para los Ingenieros, donde se fijaban las principales características que debían cumplir las representaciones gráficas de sus proyectos.

Así, se recomendaba que la representación tuviese una forma horizontal, orientado el Norte hacia su parte superior (art. 1) y que tuviese una escala en las cuatro métricas usuales (art. 3) junto a la orientación de los puntos cardinales (art. 18).

De la propuesta, tendría que hacerse un borrador y luego pasarlo a limpio (art. 22); y por menor que fuera la obra, ésta se habría de formalizar por medio de un Proyecto, Planos, Perfiles, Elevación, y Relaciones, (art.30), firmarse por el ingeniero (art. 30), y enviarse por duplicado (art.31) ( $\left.{ }^{41}\right)$.

Se han analizado las secciones de los proyectos de estos ingenieros, a través del Perfil, según guarda la Ordenanza (1718). La 
definición de perfil o sección aparece en los Apuntes sobre Dibujo y Arquitectura (1776) del cadete José Fernández de Olarte:

El Perfil sirve para representar la común sección de un plano vertical, y un cuerpo: esto es la altura, grueso, y declibio por la parte que es cortado el edificio; así mismo espresa todas las obras que de la fortificación son vistas, y no cortadas: para su exactitud bájense perpendiculares de todos los objetos (que son vistos y cortados) sobre la línea que determina la posición de la vista, o bien llamada de proyección; y las distancias de ella comprehendidas entre las perpendiculares manifestaran la apariencia de los cuerpos donde se bajaron; y dándoles sus correspondientes alturas se tendrá delineado el Perfil que representa los cortes, y obras que son visibles desde dicha línea [fol. 15v-16v (1718)] $\left({ }^{42}\right)$

En la delineación y el lavado de los proyectos de los ingenieros se identifican diversos colores. En sus expresiones gráficas, el color negro delineaba y repasaba los contornos de las formas y era utilizado para la redacción de textos o leyendas explicativas y para escala gráfica; usándose la tinta china o tinta metaloácida. Con el color amarillo se lavaban las partes proyectadas de una obra todavía no construidas; utilizándose la goma guta o gutagamba. El carmín servía para lavar las zonas existentes de una fortificación, en línea continua, y las partes que iban a ser derribadas, en la línea punteada; se realizaba con cochinilla animal o de palo de Brasil. Con el color verde se representaban los lagos, ríos y mares; para su obtención se podía emplear verde destilado, verdigrís molido con vinagre y tártaro, verde de iris, verde vejiga y verdusco oscuro $\left({ }^{43}\right)$.

\subsection{Las bóvedas tabicadas}

El sistema constructivo de bóvedas tabicadas se ejecuta mediante la acción combinada de capas de rasillas de ladrillo de pequeño espesor. La primera de estas hojas cerámicas que forma el intradós está tomada con pasta de yeso, mientras que las demás también lo pueden estar con mortero de cal. Las rasillas se disponen a tabla y tangentes a la directriz de la bóveda y las superiores colocadas a matajuntas y en diferentes direcciones. La principal característica de este tipo de construcción es la utilización del yeso como aglomerante. Este material amasado con agua produce la rehidratación y reacciona hacia una cristalización con un aumento de la temperatura, la resistencia y el volumen inicial en un corto plazo tiempo. Su utilización se reserva para la cubrición de naves, cúpulas, construcción

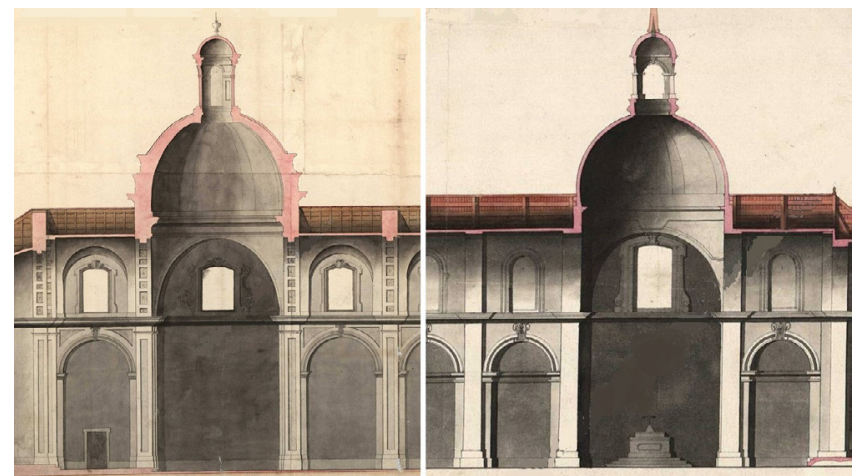

Figura 6. Ciudadela Barcelona, a) Anónimo, cúpula mampostería (c.1717); b) F. de la Pierre, bóveda tabicada (1724). de soporte de pisos y escaleras. Podemos comparar la diferencia entre la construcción con bóvedas tabicadas y las de mampostería. Es el caso de las dos versiones para la cúpula de la iglesia de la ciudadela de Barcelona. Un primer proyecto (c.1717) de autor desconocido [MPD, 02, 047] [1] realizado con cantería (Figura 6.a) y, posteriormente, otro ensayo (1724) de Francisco de la Pierre (f. 1690-1760) [MPD, 16, 024] con bóveda tabicada (Figura 6.b). En las secciones se puede observar la gran diferencia de espesores de ambas fábricas y, por tanto, la gran diferencia entre masa de obra y contrarresto de empujes.

La diferencia de los sistemas constructivos se puede comprobar en los dos proyectos redactados por Carlos Berenguer (16981756) para la construcción de una garita en Alicante: Plano, $y$ Perfil de una Garita que se propone executar inmediato al Almazén de Polvora para su custodia (1751) [MPD, 06, 167] (Figura 7.a) y Perfil, y Vista de Una de las garitas proyectadas de Piedra de sillería, para la Plaza de Alicante (1752) [MPD, 06, 161] (Figura 7.b). Entre ambos se evidencia la diferente rapidez de ejecución: el término "executar inmediato" para la bóveda tabicada de una rosca, frente a "piedra de sillería". Esta última es más resistente, pero presenta una gran diferencia en cuanto al material que se tiene al abasto y al plazo de ejecución.

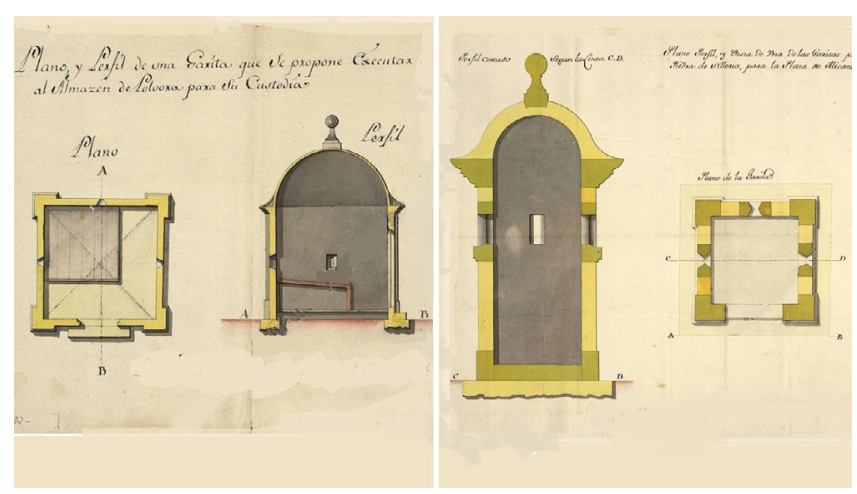

Figura 7. Proyectos de garita en Alicante, Carlos Berenguer [MPD, o6, 167] (1751); b) [MPD, 06, 161] (1752)

Estos sistemas se utilizan también para pequeñas construcciones abovedadas como el de una garita de vigía o el cupulín de una capilla. Tal es el caso del proyecto de la Capilla en el Muelle de Levante de Málaga (1727) de Juan de la Feriére (f. 1724-1737) [MPD, 29, 091] y [MPD, 08, 197] (Figura 8).
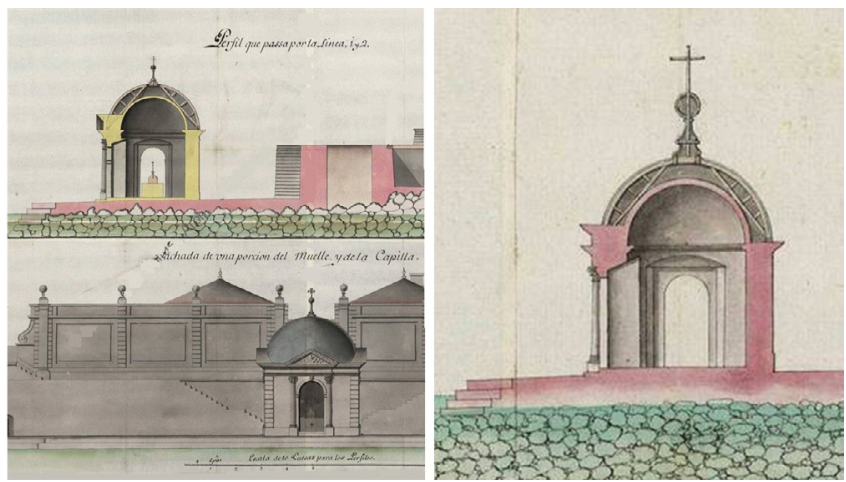

Figura 8. Capilla en el Muelle de Málaga (1727), de Juan de la Feriére a) $[M P D, 29,091]$; b) [MPD, 08, 197] 


\subsection{Bóvedas tabicadas en naves de edificios}

Desde el siglo XVII, existía una práctica en arquitectura civil de utilizar la bóveda tabicada para la cobertura de las naves en edificios religiosos. El sistema, sometido a su propio peso y a una sobrecarga de mantenimiento, dispone de unos empujes y estriado menor que las iglesias construidas con mampostería. Sobre estas bóvedas, la cubierta de los edificios presenta diferentes tipologías de cubiertas inclinadas o planas. Es el caso de la cubierta plana e inclinada del proyecto para el extremo del coro de la iglesia de la Ciudadela de Barcelona (1718) de Alejandro de Rez (f. 1710-1729), [MPD, 08, 104], (Figura 9.a), o el caso de la cubierta inclinada a dos aguas de la nueva parroquia de San Julián en el Ferrol (1764) de Pedro Ignacio de Lizardi (f. 1760-1775), [MPD, 15, 017] (Figura 9.b).

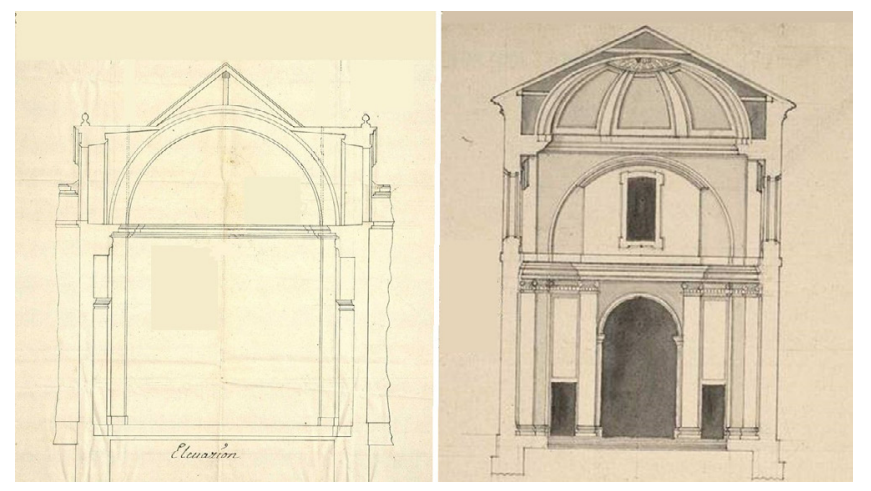

Figura 9. Bóvedas bajo cubierta, a) Barcelona plana e inclinada [MPD, 08, 104]; b) El Ferrol a dos aguas [MPD, 15, 017].

\subsection{Cúpulas tabicadas}

La arquitectura militar recoge el simbolismo de las cúpulas empleadas en la arquitectura religiosa y las utiliza como elementos de representación de la hegemonía dentro de algunos recintos militares, según puede observarse en diferentes proyectos para el arsenal de Barcelona. Por ejemplo, en el Perfil de todo el edificio cortado en la línea B.H.I de la Planta horizontal del Arsenal que se ha de construir en la ciudadela de Barcelona (1717) de Jorge Próspero de Verboom (1665-1744), [MPD, 14, 003] (Figura 10.a), u otro diseño posterior (1730) de Andrés de los Cobos, (f. 1700-1737), [MPD, 18, 004] (Figura 10.b) que aparece también sin firmar [MPD, 18, 005] como duplicado exigido por la Ordenanza de 1718.
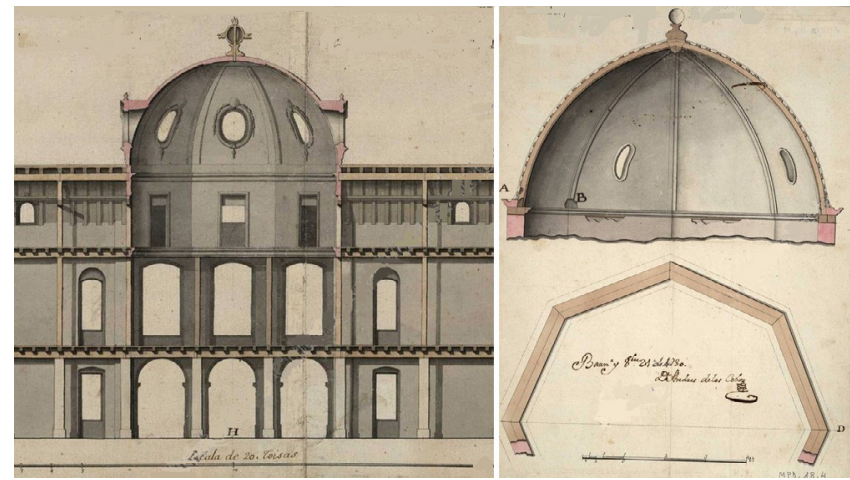

Figura 10. Cupulas para el Arsenal de Barcelona:

a) Jorge Próspero de Verboom (1717) [MPD, 14, 003], b) Andrés de los Cobos (1718) [MPD, 18, 004],

\subsection{Bóvedas tabicadas en forjados}

Las tipologías de forjado en las construcciones miliares son muy variadas. Aunque la más utilizada sea la de bovedilla cerámica entre vigas de madera (Figura 10.a), existen proyectos con forjados de madera o bóvedas de ladrillo de canto. Disponemos de evidencias de utilización de bóvedas tabicadas en el Cuartel de la Lonja en Barcelona (1741), [MPD, 18, 091] de Miguel Marín (f. 1718-174) (Figura 11.a), con detalle de la sección específica del proyecto [MPD, 18, 091]. Un caso muy particular son las bóvedas del proyecto Plano, Perfil y Elevación del cuartel nuevo de Caballería, unido a la Real Academia de Matemáticas en la Plaza de Barcelona, capaz para un Escuadrón (1759) de Pedro Martín Cermeño (1722-1792), [MPD, 10, 012] (Figura 11.b). En este proyecto, las bóvedas principales están trabadas con la arquería mediante unas lengüetas en su trasdós. Estos elementos, situados simétricamente sobre la bóveda principal, están construidos en forma de revoltón, aunque de factura algo inclinada y sirven además para sustentar el solado del piso.

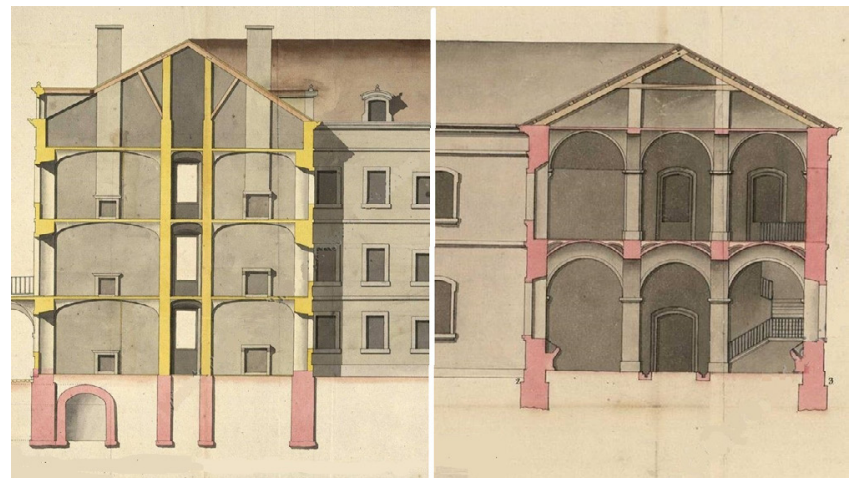

Figura 11. Bóvedas tabicadas forjados Cuarteles Barcelona, a) Miguel Marín (1741) [MPD, 18, 091]; b) Martín Cermeño (1759) [MPD, 10, 012]

\subsection{Escaleras tabicadas}

Uno de los elementos que ha perdurado y que ha llegado a nuestros días es la escalera tabicada difundida por Manuel Fornés Gurrea (1777-1856), en sus Observaciones sobre la práctica del arte de edificar, [fol 19-22 (1841)] (44).

La utilización de este sistema mediante la descarga de una curva de arco permite una gran flexibilidad del replanteo a tirajes diferentes de escaleras. Por otra parte, la rehidra-
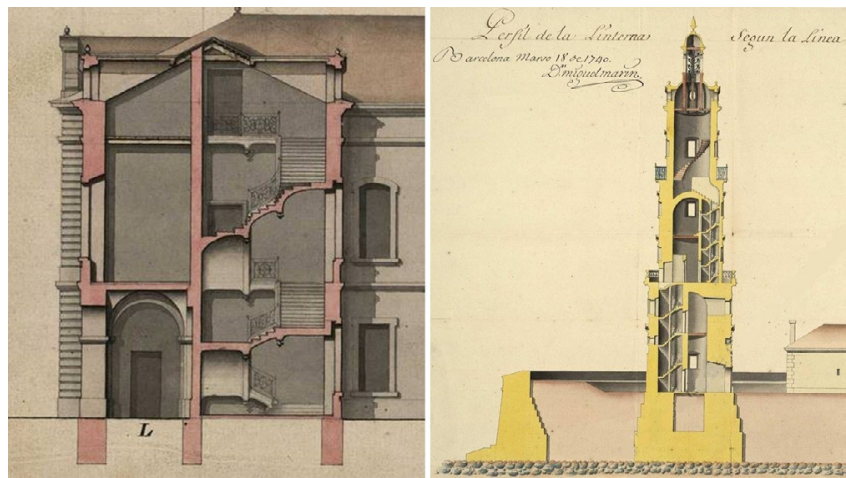

Figura 12 Detalle escaleras bóveda tabicada en Barcelona, a) Jorge Prosper Verboom (1717) [MPD, 14, 002]; b) Miguel Marín (1740) [MPD, 07, 128] 
tación de la masa del yeso hace que se produzca un efecto de cristalización con un rápido endurecimiento del material, lo que permite una ejecución muy rápida por la escasez de elementos auxiliares. Este sería el caso del proyecto del Perfil cortado en la línea L.M.N del Arsenal que se ha de construir en la Ciudadela de Barcelona (1717) de Jorge Prosper Verboom (1665-1744,) [MPD, 14, 002] (Figura 12.a).

Si el proyecto anterior partía de una escalera de tramos rectos, también hemos podido analizar el diseño de una escalera helicoidal, en este caso proyectada por Miguel Marín (f. 1718-1742). Su primera versión bajo el título Perfil de la Linterna según la línea $C$. D. de los muelles proyectados en Barcelona, con sus baterías a la cabeza, cuerpos de guardia, almacenes de pólvora y cisternas (1740), [MPD, 07, 013] (Figura 12.b) es rectificada posteriormente como Elevación de la linterna con la de la batteria eliptica según la línea puntuada R.S. (1743), [MPD, 07, 128]. En ambos casos se mantiene una tipología similar a la de la escalera inicialmente proyectada.

\subsection{Empujes de bóvedas}

La revisión de la teoría del Conde de Espié (1765) sobre el monolitismo y los empujes de las bóvedas tabicadas ya fue contestada por Juan de Herrera (1776), pero tenemos una evidencia anterior en la que existe constancia del conocimiento, por parte de los ingenieros españoles, del estribado de estas bóvedas. Es el caso del proyecto del Cuartel de Orihuela (1747) de Pedro Torbe, (f. 1743-1772), en una primera sección de 3 de agosto, realizada por el acceso al acuartelamiento: Perfil cortado según la línea A.BB, y C. del Cuartel de Orihuela (1747), [MPD, 27, 062]. (Figura 13.a).

Posteriormente, hay una modificación de la sección, de 21 de octubre: Perfil de una de las Alas del Quartel de caballeria, el que representa la nueba disposicion de su cubierta, $y$ juntamente la Abitacion que quedara para los soldados, y Omenages a la Tropa (1747), [ MPD, 67, 080] (Figura 13.b) En la explicación de esta modificación se especifica: 8, Encamonada para recibir el texado, y juntamente sirben á estribar el cañón de la Bobeda de otros Desvanes. En primer lugar, se observa en la modificación una sección más esbelta y con mayor pendiente en la cubierta, y en segundo, la definición que tiene la encamonada con la función específica de operar a manera de las lengüetas para atirantar este tipo de bóvedas.

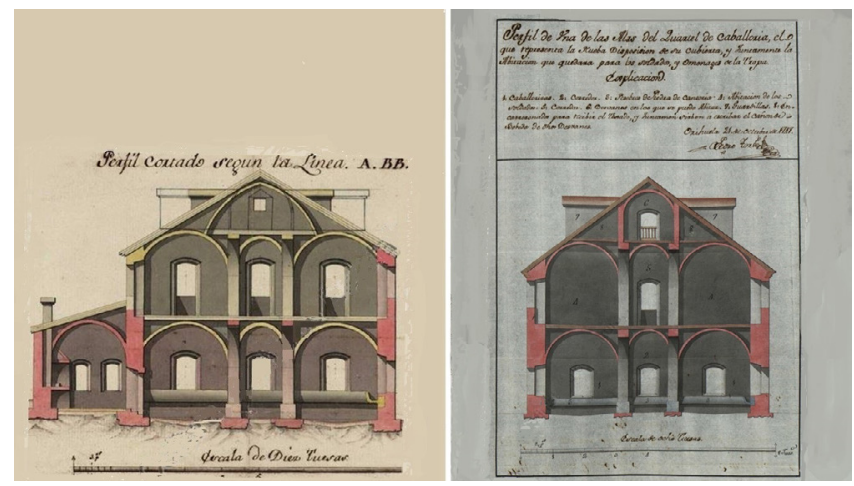

Figura 13. Cuartel Orihuela Pedro Torbe (1747). Empuje bóvedas, [MPD, 27, 062], [MPD, 67, 080].

\subsection{Bóveda a prueba de fuego}

El conocimiento de las propiedades contra el fuego de las bóvedas tabicadas que se manifiesta en los textos del Conde de Espié (1765), de Sotomayor (1776) o de Patte (1777), que se cita textualmente en el del Proyecto del Cuartel de la Puerta de los Pozos dirigido a Sabatini (1794): Plano y perfil de una nueva forma para edificar un Cuartel de Infantería con arreglo al pie moderno y ventajoso al método que hasta aquí se ha seguido, [AGMS [2]. Signatura: 3 a $/ 3^{\mathrm{a}} /$ Legajo 577] (Figura 14).

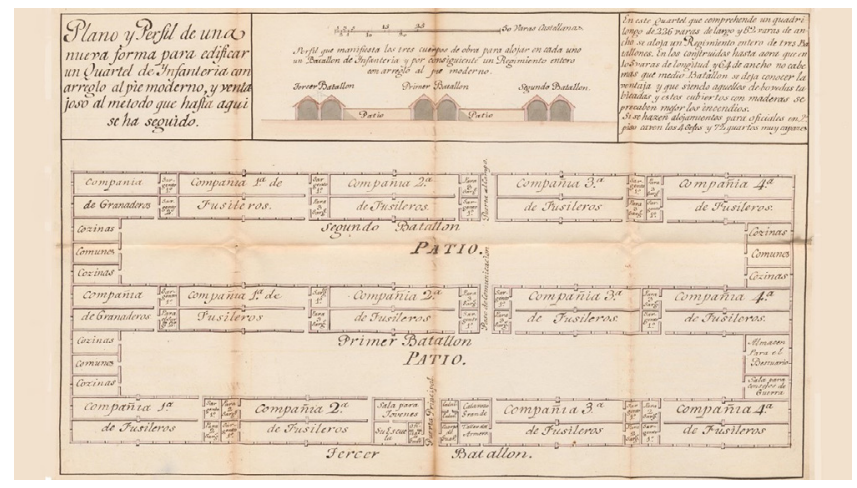

Figura 14. Proyecto cuartel en Madrid (1794) con bóvedas que precaven mejor los incendios [AGMS Sig. 3 a / 3 a Leg. 577]

El cuartel se situaba en la puerta de pozos de nieve de Madrid, y remite a Francisco de Sabatini como Director y Comandante General en propiedad de caminos, puentes, edificios de arquitectura civil y canales de riego y navegación, e Inspector General de los ramos de Academias y Fortificaciones (17911797) y también como proyectista de alguna de la Puertas de Madrid y como conocedor del texto de Patte (1777) en su biblioteca. En la leyenda del proyecto se indica las ventajas del nuevo sistema métrico, y constructivo:

se deja a conocer la ventaja y que siendo aquellos de bovedas tabicadas y estos con maderos se precaven mejor los incendios.

\section{CONSTRUCCIONES NO DEFENSIVAS DE LOS INGENIEROS MILITARES DEL SIGLO XVIII}

En la tratadística formativa de los ingenieros se aborda la construcción de elementos no defensivos. Así lo indica la traducción hecha por Miguel Sánchez Taramas (1733-1799) del título A treatise containing the elementary part of fortification, regular and irregular (1755) de John Müller por Tratado de fortificación, ó Arte de construir los edificios militares, $y$ civiles (1769). Esta obra dedica la Sección XIX a los polvorines y la XX a los cuarteles, arsenales y hospitales. Respecto a los cuarteles matiza los dedicados al Cuerpo de Caballería por la necesidad específica de la construcción de las caballerizas respecto a las demás armas. Miguel Sánchez Taramas introduce unas Adiciones para la readaptación ibérica del tratado de John Müller con las características constructivas propias. Por su parte Los Principios de Fortificación (1772) de Pedro de Lucuze, hace referencia en su Capítulo XIX a los Edificios Principales a los que define como edificios militares: los alojamientos del Estado Mayor, cuarteles, pabellones, hospitales, almacenes de víveres y munición, iglesia y cisterna, considerándolos constructivamente como tipo sencillo o como tipo a prueba de bomba. 


\subsection{Cuarteles}

En las adiciones de Miguel Sánchez Taramas (1733-1799) del Tratado de fortificación, ó Arte de construir los edificios militares, $y$ civiles (1769), se hace referencia en la Lámina $\mathrm{n}^{0} 7$ al proyecto del Cuartel de Caballería de Reus (Figura 15) de Juan Martín Cermeño (1700-1773) titulado Plano ynferior del quartel y pavellones que se esta executando en la Villa de Reus capaz de 700 ynfantes, un esquadrón de cavalleria y los correspondientes oficiales, cuio proyecto se deve seguir igualmente en los de Valls y Villanueba de la Geltrú (1751) [MPD, 20, 028]

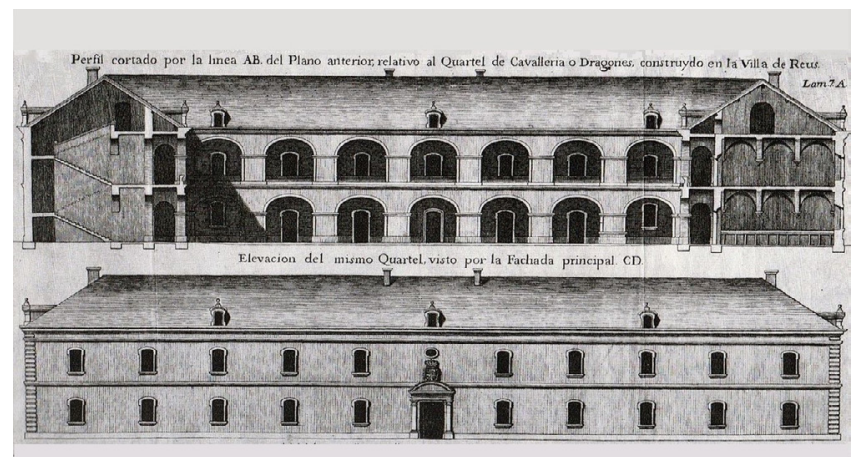

Figura 15. Miguel Sánchez Taramas Tratado de fortificación, ó Arte de construir los edificios militares, y civiles (1769). Lámina $\mathrm{n}^{0} 7$, ilustra el proyecto del Cuartel de Caballería de Reus. de Juan Martín Cermeño (1751)

Tanto el proyecto como el texto se convierten en un prototipo a seguir para poder ser reproducido como modelo tipológico. Respecto a la construcción tabicada, Miguel Sánchez Taramas dice:

Es este se manifiesta con claridad la estructura interior del Edificio, la naturaleza de sus Bovedas (que son de Tabique, y construidas por Arista), la disposcion de las Escaleras, la magnitud y numero de los Arcos y Pilares de los Corredores, la formación de la Armadura [fol-384-385 (1769)].
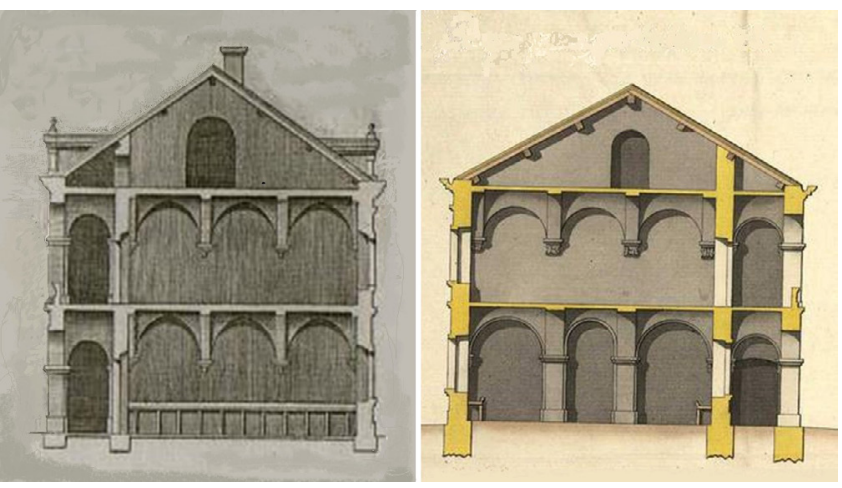

Figura 16. a) Sección Cuartel de Caballería de Reus Tratado de fortificación (1769); b) Cuartel Villafranca Penedés, Juan Martín Cermeño (1769) [MPD, o8, 136].

En este mismo año, Juan Martín Cermeño realiza el Proiecto de un Quartel que solicita eregir la Villa de Villafranca de Panades, para dos Esquadrones de Cavallería o bien un Batallon de Ynfanteria con Pavellones correspondientes para oficiales [MPD, o8, 136] (Figura 16.b). La sección del proyecto es idéntica, aunque simétrica, a la del texto del Tratado de fortificación, ó Arte de construir los edificios militares, $y$ civiles (1769) (Figura 16.a). Por consiguiente, se trata de sistematizar un modelo tipológico tanto desde la distribución formal del edifico como desde el punto de vista constructivo edilicio mediante la utilización de obra de fábrica cerámica en muros, pilares, arcos y bóvedas tabicadas. El sistema ya fue utilizado con anterioridad por Nicolás Agustín Bodin y de Bellet (f. 1718-1753) para la construcción de acuartelamientos, como es el caso de los proyectos de Planta y dos perfiles del cuartel de Alicante que se proyecta (1739) [MPD, 25, 095] (Figura 17.a) y del Plano, Perfiles y elevaciones de un Quartel de Cavallería para abitación de 200 soldados... que devera colocarse en... (1741) [MPD, 10, 092] (Figura 17.b).

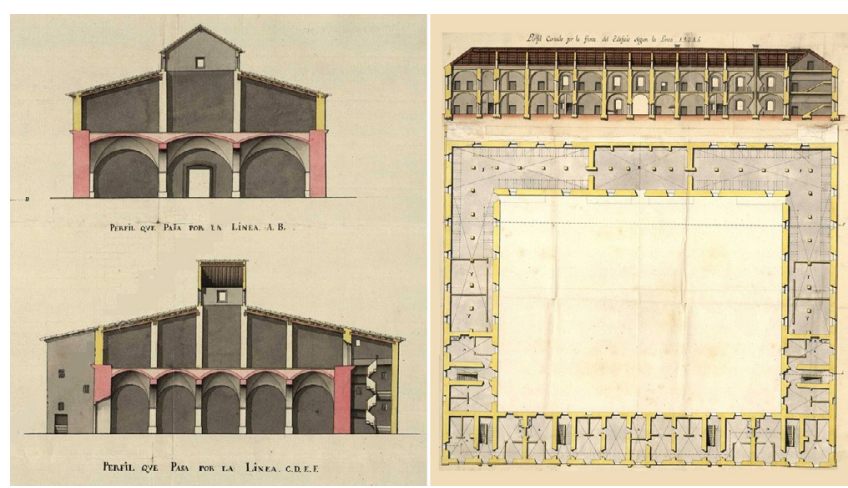

Figura 17. Nicolás Agustín. Bodin a) Cuarte de Alicante (1739)

[MPD, 25, 095]; b) Cuarte de Orihuela (1741) [MPD, 10, 092]

\subsection{Caballerizas}

Mientras que los cuarteles para el alojamiento de tropas se han de alojar cerca de los baluartes, la ubicación de aquellos de caballería, regidos por la utilidad de los caballos y por el requerimiento de su mantenimiento, tienen en especial la necesidad de agua para su higiene y manutención, por ello su ubicación está relegada a esta necesidad. La disposición de las caballerizas está construida en dos crujías: una para el estabulario y la otra para la circulación y mantenimiento de los caballos. En los casos en que los establos tengan solo una planta, se cubren mediante bóvedas tabicadas, según se muestra en los proyectos de Pedro Torbe (f. 1743-1772), Plano inferior del Cuartel de Caballería que se está construyendo extramuros del Arrabal de la ciudad de Orihuela, Proyecto de aumento de Caballerizas (1747), [MPD, 27,

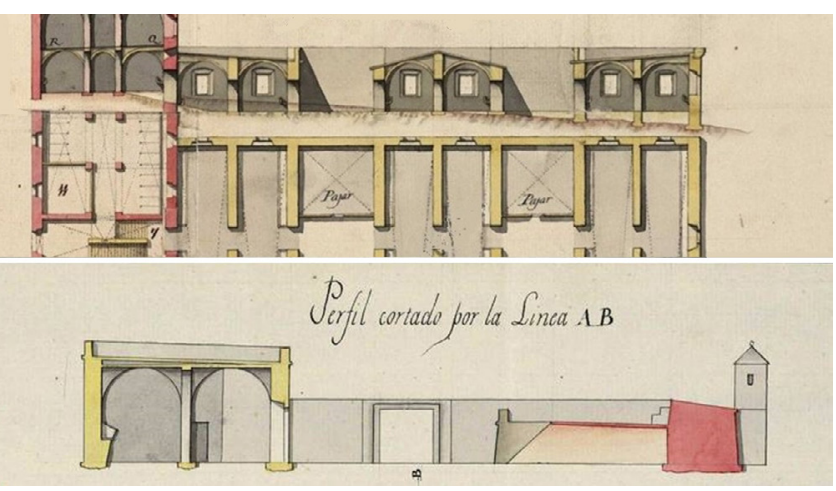

Figura 18. Caballerizas, a) P. Torbe, Orihuela (1747), [MPD, 27, o61]; b) F. Pirez, Málaga (1796), [MPD, 65, 029] 
o61] (Figura 18.a) y Plano del fuerte llamado San Carlos, situado en la Costa de Levante de la Ciudad de Málaga (1796) [MPD, 65, 029] de Fernando Pirez (f. 1788-1801) (Figura 18. b)

\subsection{Almacenes de víveres}

Dice Pedro de Lucuze que los almacenes se han de construir en lugares secos, repartidos y no muy distantes de los cuarteles. Este el caso particular del proyecto para almacén de sal en Zaragoza que, por las especiales condiciones del condimento y por la necesidad de ser albergado en un lugar con poca humedad, fue edificado mediante sistema tabicado. El proyecto es del ingeniero Narciso Brer y Miró (f.1769) y se titula Plano y Perfil del Almacen de Sal que se propone en el Lugar de Remolinos del Reyno de Aragon (1769) [MPD, 68, 097]. (Figura 19).

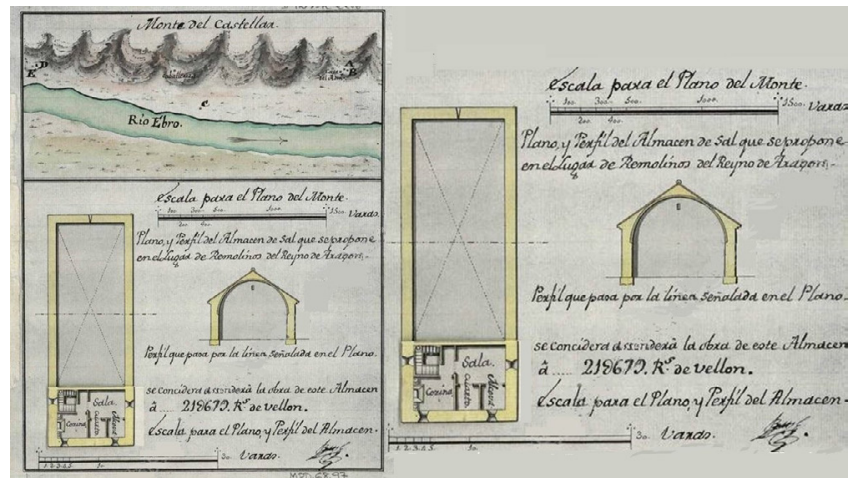

Figura 19. Almacén de sal en Zaragoza (1769) [MPD, 68, 097]

\subsection{Almacenes de munición}

Recomienda Müller [vol.1 fol.367(1767)] que los almacenes de pólvora no se edifiquen dentro de las plazas y aconseja hacerlos de tamaño medio y a una distancia competente para que puedan servir de repuesto entre ellos. En la construcción de estos almacenes de pólvora se ha observado la utilización de bóvedas tabicadas.

Es el caso de utilización de dos bóvedas a pleno punto de cañón, proyectadas a media legua de Cartagena (1743) [MPD, 18, 256] por Pedro Torbe (f. 1743-1772) (Figura 20.a) y, también, el caso de la bóveda rebajada utilizada en el repuesto de pólvora que se proyecta en el Torreón

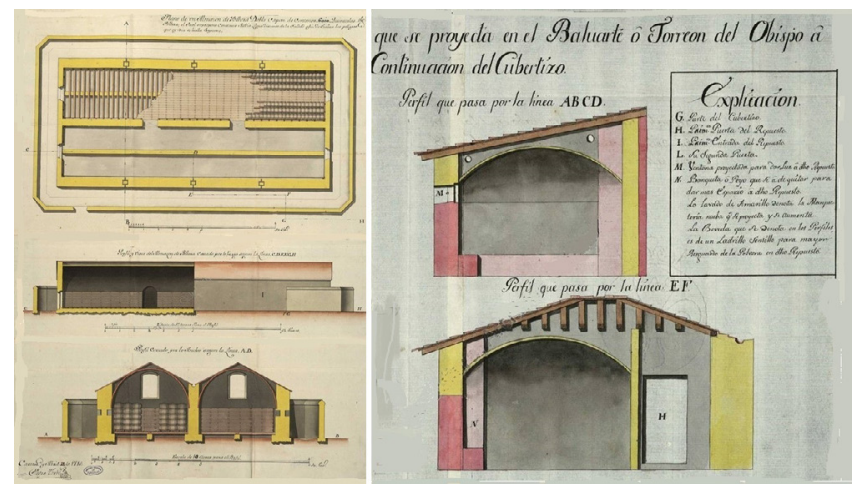

Figura 20. Polvorines; a) Cartagena P. Torbe (1743) [MPD, 18, 256]; b) Málaga, G.Amici (1748) [MPD, 57, 052] del Obispo de Málaga (1748) [MPD, 57, 052] por Gerónimo Amici (c.1700-1764) (Figura 20.b). Indica el autor que: La Boveda que se Denota en los Perfiles es de un Ladrillo Sencillo para mayor Resguardo de la Polvora en dtho. Repuesto.La única función de la bóveda es la creación de un espacio ventilado entre el depósito de la munición y la cubierta, cumpliendo con el criterio de diseño de los polvorines de Bélidor (1729), Müller (1769) y Lucuze (1772).

\subsection{Edificios principales}

En las instrucciones de Pedro de Lucuze se refiere la existencia de edificios representativos situados en la plaza principal del arsenal o de las plazas fortificadas.

Como ejemplos de construcciones tabicadas en estas tipologías tenemos el proyecto de Juan Caballero (1713-1791) para la Aduana de Cádiz (1769), [MPD, 14, 025] (Figura 21.a.) o la Sala de Armas del Ferrol (1769) [MPD, 51, 019] de Julián Sánchez Bort (1725-1781). (Figura 21.b)

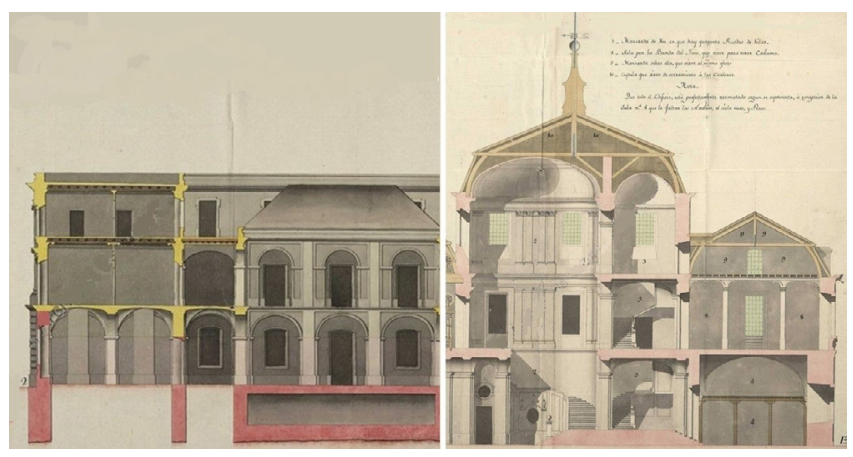

Figura 21.a) Aduana Cádiz Juan Caballero (1769) [MPD, 14, 025]; b) Casa de Armas Ferrol Julián Sánchez Bort (1769) [MPD, 51, 019].

\subsection{Hospitales}

John Müller dimensiona los Hospitales en función de la guarnición de la plaza, utilizando el criterio de una cama por cada cien soldados. Por su parte Pedro de Lucuze aboga por su situación dentro de la Plaza Fuerte, estando apartado y cercano a un lugar con suministro de agua. Para esta tipología de edificios de estructura similar a la de los cuarteles, damos cuenta del proyecto para el Hospital de Algeciras (1745) [MPD, 27, 059] de Lorenzo de Solís (16931761). (Figura 22)

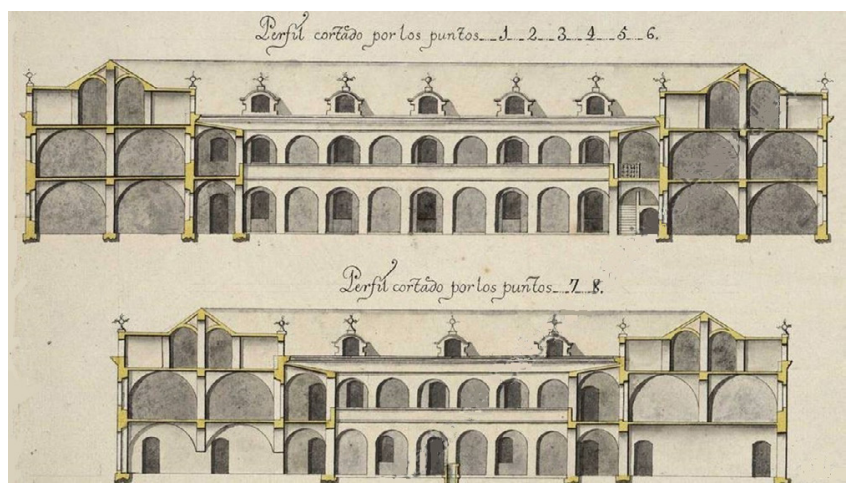

Figura 22. Hospital de Algeciras de Lorenzo de Solís (1745), [MPD, 27, 059] 


\subsection{Iglesias}

Las iglesias del recinto fortificado, según John Müller y Pedro de Lucuze, deben ocupar el sitio principal de la plaza, cerca de la casa del Gobernador. También se proyectan las capillas como elemento auxiliar dentro de los hospitales, para asistencia espiritual de enfermos o heridos.

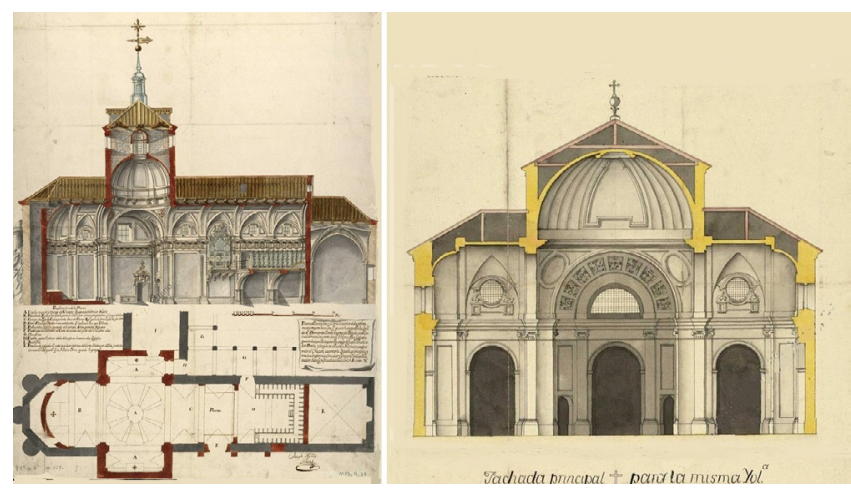

Figura 23. Iglesias; a). Toledo José Hernández Sierra (1748) [MPD, 09, 038]; b) Ferrol de Julián Sánchez Bort (1763) [MPD, 05, 053]

Entre estos proyectos se encuentra Planta, Elevación y Corte interior de la Obra más proporcionada que puede hacerse en la Iglesia de San Bernardo Extramuros de Toledo (1748), [MPD, 09, 038] de José Hernández Sierra (c.1705-1782) (Figura 23.a) así como Representación interior de la iglesia parroquial proyectada para la ciudad nueva del Ferrol; $\mathrm{Fa}$ chada principal para la misma iglesia (1763) de Julián Sán-

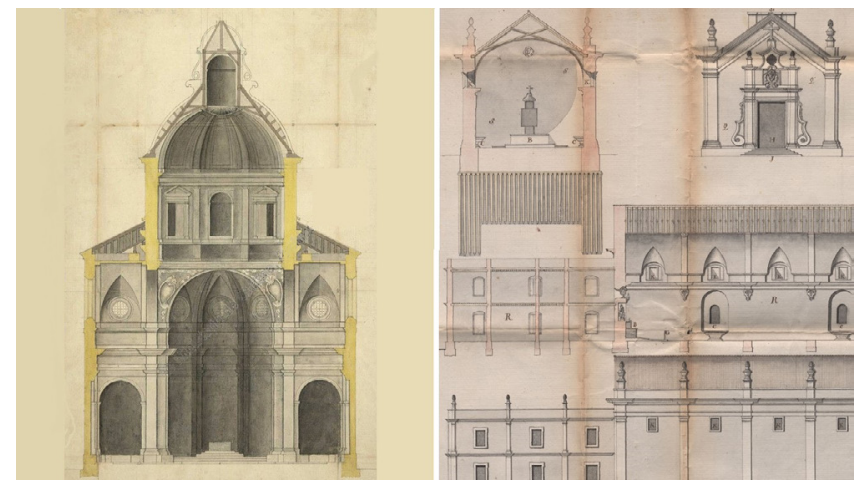

Figura 24. Iglesia para Arsenales a) Ferrol, Pedro Ignacio de Lizardi (1764) [ MPD, 05, 055.]; b) Cádiz, Francisco Autrán de la Torre (1785) [MNM, Sig. MN-P-2E-36 chez Bort (1725-1781), [MPD, 05, 053] (Figura 23.b) y otros proyectos para arsenales como el del Ferrol (1764) [ MPD, o5, 055.] de Pedro Ignacio de Lizardi (f. 1760-1775) (Figura 24. a) y el de la Carraca de Cádiz y su iglesia (1785) [MNM, Sig. MN-P-2E-36] de Francisco Autrán de la Torre (1736-1792) (Figura 24. b).

\section{CONCLUSIÓN}

La fortuna crítica del redescubrimiento del sistema de las bóvedas tabicadas por parte del Conde de Espié (1754) y difundidas por Patte (1777) tuvo más incidencia teórica entre los arquitectos de mérito de la Real Academia de San Fernando a través de Diego de Villanueva que entre los de la Academia de Matemáticas de Barcelona, ya que cronológicamente no coincidió con sus planes de estudio.

El Cuerpo de los Ingenieros Militares utilizó las bóvedas tabicadas para la construcción de cúpulas, bóvedas y escaleras como un sistema constructivo local de mano de obra especializada que se había utilizado en la Península Ibérica desde el siglo XIV. Muestra de ello es el proyecto del Cuartel de Caballería de Orihuela (1747), [MPD, 27, 061] (Figura 1.b; 18.a), que es anterior a la publicación del Conde de Espié (1754) y coetáneo al Castillo de Bizy (1740). Miguel Sánchez Taramas (1769) recomienda la construcción tabicada para los Cuarteles de Reus (1751), constatando que este sistema ya había sido utilizado por Nicolás Agustín Bodin y de Bellet en los acuartelamientos de Alicante (1739) [MPD, 25, 095] y de Orihuela (1741) [MPD, 10, 092] (Figuras 17.a, b).

La construcción tabicada se utiliza en el Plan de la Ciudadela de Barcelona, desarrollada por Jorge Prospero Verboom. Él mismo la utilizará en la cúpula del Arsenal (1717), [MPD, 14, 003] (Figura 10.a) mientras que en las mismas fechas se sirvieron también de ella Andrés de los Cobos [MPD, 18, o04] (Figura 10.b) y Francisco de la Pierre (f. 1690-1760) [MPD, 16, 024] (Figura 6.b). Sus proyectos son anteriores a la Real Ordenanza de 1718 y a la enseñanza en la Academia de Matemáticas de Barcelona (1720). La construcción con bóvedas tabicadas era habitual en la construcción civil, en todo el Levante español donde se encuentran la mayoría de estos proyectos. Por tanto, existe una rápida asimilación, desde el inicio de la creación del Cuerpo de Ingenieros Militares, de la utilización de este sistema constructivo que había sido utilizado en este territorio durante más de tres siglos.

\section{NOTAS}

(1) MPD: Mapas, Planos y Dibujos del Archivo General de Simancas.

(2) AGMS: Archivo General Militar de Segovia

(3) MNM: Museo Naval de Madrid

\section{REFERENCIAS / REFERENCES}

(1) Contant d'Ivry, P. (1769). Les Oeuvres d'architecture de Pierre Contant d'Ivry, architecte du Roi. Première partie. Paris:Chez Dumont professeur d'architecture.

(2) Araguas, Ph. (1999). Voûte à la Roussillon. Bulletí de la Reial Acadèmia catalana de Belles Arts de Sant Jordi, nº XIII, pp. 173-185.

(3) Zaragozá A (2012). Hacia una Historia de las Bóvedas Tabicadas. En: Construyendo Bóvedas Tabicadas. Actas del Simposio Internacional sobre Bóvedas Tabicadas Valencia 26, 27 y 28 de mayo de 2011, Zaragozá, A, (et alt) (ed.). Valencia: Universitat Politèc-nica de Valencia pp. 11-46. 
(4) D’Espie, F.F. (1756). Réflexions du Comte D. Offcier d'Infanterie, Chevalier de l'Order Royal \& Militare de St. Louis. Sur l'établissement de l'École militaire. (S.I.)

(5) D’Espie, F.F. (1754). Maniere de rendre toutes sortes d'édifices incombustibles; ou Traité sur la construction des voutes faites avec des briques \& du plâtre dites voutes plates; \& d'un toit de brique sans charpente appellé comble briqueté. Paris: Duchesne, pp. 2-12.

(6) Sotomayor, J. (1776). Modo de hacer incombustibles los edificios, sin aumentar el coste de su construccion extractado de el que escriviò en francés el conde de Espie; ilustrado y añadido por Joachin de Sotomayor Cisneros y Sarmiento. Madrid: En la oficina de Pantaleón Aznar.

(7) Lemonier, H. (1929). Procès verbaux de l'Académie royale d'Architecture 1671-1793. T.VI, (pp.74-82). Paris: Armand Colin.

(8) Huerta, S. (2001). La mecánica de las bóvedas tabicadas en su contexto histórico, con particular atención a la contribución de los Guastavino. En: Las bóvedas de Guastavino en América, ed. S. Huerta, (pp. 87 $\square$ 112). Madrid: Instituto Juan de Herrera, CEHOPU.

(9) González Moreno-Navarro J, L. (2004). La bóveda tabicada: pasado y futuro de un elemento de gran valor patrimonial. En: Construcción de bóvedas tabicadas, Truño, A. (ed). Madrid: Instituto Juan de Herrera, pp. Xi-Lx.

(10) Guastavino, R. (1892). Essay on the Theory and History of Cohesive Construction applied especially to the timbrel vault, (pp. 45). Boston: Ticknor and Company.

(11) Huerta, S. (2006). La construcción tabicada y la teoría cohesiva. En: Guastavino, R. Escritos sobre la construcción cohesiva y su función en la arquitectura, (pp. XV-LX). Madrid: CEHOPU, Instituto Juan de Herrera.

(12) Villanueva, Diego de (1766). Colección de Diferentes Papeles Críticos sobre todas las partes de la Arquitectura. Valencia: Impreso por Benito Monfort.

(13) Laugier, M. A, (1753). Essai sur l'architecture. Paris: chez Duchesne, rue S. Jacques, au Temple du Goût. M. DCC. LIII. Avec approbation \& privilege du Roy.

(14) Frémin, M. de (1702). Mémoires critiques d' architecture. Contenans l’idée de la vraie \& de la fausse architecture ... par Frémin. Paris: Charles Saugrain.

(15) VV. AA. (1747). Mercure de France: dédié au Roy, 14 vols. Paris; La Veue Pissot, Jean de Nully, Jacques Barros, Andre Calleau.

(16) Frezier, A. F, (1737-1739), La Théorie et la Pratique de la Coupe des Pierres et des Bois, pour la Construction de Voutes et autres Parties des Bâtiments Civils \& Militaires, ou Traité de Stereotomie a l'Usage de l'Architecture, 3 vol. Strasborg: J. D. Doulsseker, Paris: L.H. Guérin.

(17) Laugier, M. A (1765). Observations sur l'Architecture. Par M. L'Abbé Laugier, des Académies d'Angers, de Marseille \& de Lyon. La Haye: Et se trouva à Paris, Chez Desaint.

(18) Fray Lorenzo de San Nicolás (1639). Arte y uso de la arquitectura. Dirigida al Smo. Patriaca S. Ioseph, Compiesto por Fr. Laurencio de S Nicolas, Agustino Descalço, Maestro de Obras. Juan Sanchez.

(19) Fray Lorenzo de San Nicolás (1665). Segunda parte del Arte y Uso Arctiitectura. Dedicada al desamparo que padeció mi redentor Jesuchristo las tres oras que estubo viuo enclabado en el Árbol de la Cruz. Con el Quinto y Séptimo libros de Euclides traducidos de latin en Romance. Y las medida difíciles de Bóvedas y de las superficies y pies cúbicos de Pechinas. Con las ordenanzas de la Imperial Ciudad de Toledo aprobadas y confirmadas por la Cesarea Magd. del Sr. Emperador Carlos V de gloriosa memoria. Compuesto por P.F. Faurencio de San Nicolas. Agustino descalzo Architecto y Maestro de obras natural de la muy noble y coronada Villa de Madrid. Madrid: Petrus Villafranca.

(20) Juan de Torija, (1661). Breve Tratado de todo Genero de bobedas Asi Regulares como irregulares execucion de obrarlas y Medirlas con singularidad y Modo Moderno observando los preceptos Canteriles de los Maestros de Architectura. Madrid: Pablo de Val.

(21) Athanasio Genaro Brizguz y Bru (1738). Escuela de Arquitectura Civil, en que se contienen los órdenes de Arquitectura, la distribución de los planos de templo y casas, y el conocimiento de los materiales. Valencia: Oficina de Joseph de Orga

(22) Schübler: J.J. (1749). Das ist: Kurtze und leichte Verfaßung der Practicabelsten Regul, zur Perspectivischen Zeichnungs-Kunst. Worinnen gezeiget wird, wie man alles, was in der Architectur zu finden ist, auf das geschwindeste in das Perspectiv bringen . Erster Theil. Nürnberg: Verlag Christoph Weigel, Kunsthändler.

(23) Plo y Camín, A. (1767). El Arquitecto Práctico, Civil, Militar, y Agrimensor, dividido en tres libros. Madrid: Imprenta de Pantaleon Aznar.

(24) Blondel, J.F.; Patte, M. (1777). Cours d'architecture, ou, Traité de la décoration, distribution \& construction des bâtiments . Tome sixiéme. Paris: Chez la Veuve Desaint.

(25) Blondel, J.F.; Patte, M. (1777). Planches por le sixiéme volumen du cours d'Architecture, comencé par feû J. F. Blondel et continue par M. Patte. Paris: Chez la Veuve Desaint.

(26) Carrillo de Albornoz, J. (2004). Els plans d'estudi a l'Acadèmia de Matemàtiques i el seu funcionament intern. En: $M u-$ ñoz, J. M. (coor.) L’Acadèmia de Matemàtiques de Barcelona. El llegat dels enginyers militars (pp.103-115). Madrid: Ministerio de Defensa.

(27) Muller, J. (1769). Tratado de fortificación, ó Arte de construir los edificios militares, y civiles escrito en ingles por Juan Muller; traducido en castellano, dividido en dos tomos, y aumentado con notas, adiciones y 22 láminas finas sobre 26, que ilustran al original, por Miguel Sanchez Taramas. Barcelona: Por Thomas Piferrer.

(28) De Lucuze, P. (1772). Principios de fortificación, que contienen las definiciones de los terminos principales de las obras de Plaza y de Campaña... dispuestos para la instrucción de la juventud militar. Barcelona: Thomas Piferrer.

(29) De March J. I. (1781). Nociones militares, ó Suplemento a los principios de fortificacion del Señor Don Pedro de Lucuze escrito para la instrucion de los Caballeros Cadetes del Regimiento de Dragones de Sagunto Barcelona: Impresor Bernardo Plá. 
(30) Tous Milá, J. (2018). Pedro de Lucuce. Tratado VIII de la Arquitectura Civil. Curso Matemático para a Instrucción de los Militares (1739-1779) según varios manuscritos de 1760 y 1776, pp.95-225, San Cristóbal de la Laguna: Jan Tous Meliá.

(31) Segovia, F. (2004). Els fons bibliogràfics de l'Acadèmia de Matemàtiques. En: Muñoz, J. M. (coor.) L'Acadèmia de Matemàtiques de Barcelona. El llegat dels enginyers militars (pp.77-92). Madrid: Ministerio de Defensa.

(32) Muñoz, J. M. (1995). La biblioteca del ingeniero general Jorge Próspero Verboom. Academia (80): 343-362.

(33) Ruiz Hernando, José Antonio (1993). La testamentaría de Francisco Sabatini. En: "Francisco Sabatini (1721-1797)", Octubre-Diciembre 1993.

(34) Galland-Seguela, M. (2004). Las condiciones materiales de la vida privada de los ingenieros militares en España durante el siglo XVIII. Geo Crítica/Scripta Nova. Revista electrónica de geografía y ciencias sociales, 8 (179).

(35) Galland-Seguela, M. (2008). Les ingénieurs militaires espagnols de 1710 à 1803. Étude prosopographique et sociale d'un corps d'élite. Madrid; Bibliothèque de la Casa de Velázquez no 40. Annexe IV.

(36) Cámara, A. (2005) La arquitectura militar del padre Tosca y la formación teórica de los ingenieros entre Austrias y Borbones. En: Cámara, A. (coord.) Los ingenieros militares de la monarquía hispánica en los siglos XVII y XVIII. Madrid: Ministerio de Defensa, Asociación Española de Amigos de los Castillos, Centro de Estudios Europa Hispánica, pp. $133-158$.

(37) Galindo, J. (2000) La Ciencia de los Ingenieros. en la primera mitad del siglo XVIII”. Informes de la Construcción, vol. $52, n^{0} 467$, pp. 47-54.

(38) Tosca, T. V. (1712). Compendio mathematico. Tomo V, Que comprehende Arquitectura civil, montea, y canteria, arquitectura militar, pirotechnia, y artillería. Valencia: Antonio Bordazar.

(39) Addis, B. (2013). "Toys that save millions" a history of using physical models in structural design. The Structural Engineer, Vol. 91, $\mathrm{N}^{\circ} 4$ pp 12-27.

(40) Muñoz J. M. (2015). Jorge Próspero Verboom. Ingeniero militar flamenco de la monarquía hispánica (pp. 84-114). Madrid: Fundación Juanelo Turriano.

(41) Portugués, J. A. (1803). Colección General de las Ordenanzas Militares, sus innovaciones, y aditamentos, Dispuesta en diez Tomos, con separación de clases. Real Cuerpo de Artillería e Ingenieros, Tomo VI (pp. 753-792). Madrid: Imprenta de Antonio Marín.

(42) Fernández de Olarte, José (1776). Apuntes sobre dibujo y arquitectura. Manuscrito MSS/13694.

(43) Giménez, M. (et. alt), (2009). El color y su significado en los documentos cartográficos del Cuerpo de Ingenieros Militares del siglo XVIII. Ge-conservación, $\mathrm{n}^{\circ} \mathrm{O}$, págs. 141-146.

(44) Fornés Gurrea, M. (1841). Observaciones sobre la práctica del arte de edificar. Valencia: Imprenta de Cabredizo 